\title{
Comparison of reducing sugar content, sensory traits, and fatty acids and volatile compound profiles of the longissimus thoracis among Korean cattle, Holsteins, and Angus steers
}

\author{
Min Yu Piao ${ }^{1,2}$, Hyun Jung Lee ${ }^{1}$, Hae In Yong' ${ }^{1}$ Seok-Hyeon Beak', Hyun Jin Kim', \\ Cheorun Jo ${ }^{1,3,4}$, Komang Gede Wiryawan ${ }^{5}$, and Myunggi Baik ${ }^{1,3, *}$
}

\section{* Corresponding Author: Myunggi Baik Tel: +82-2-880-4809, Fax: +82-2-873-2271, E-mail: mgbaik@snu.ac.kr}

'Department of Agricultural Biotechnology and Research Institute of Agriculture and Life Sciences, College of Agriculture and Life Sciences, Seoul National University, Seoul 08826, Korea

${ }^{2}$ Feed Research Institute, Chinese Academy of Agricultural Sciences, Beijing 100081, China ${ }^{3}$ Institute of Green Bio Science and Technology, Seoul National University, Pyeongchang 25354, Korea

${ }^{4}$ Centers for Food and Bioconvergence, Seoul National University, Seoul 08826, Korea

${ }^{5}$ Department of Animal Nutrition and Feed

Technology, Faculty of Animal Science, Bogor

Agricultural University, Bogor 16680, Indonesia

ORCID

Min Yu Piao

https://orcid.org/0000-0002-7067-7741

Hyun Jung Lee

https://orcid.org/0000-0002-6891-8008

Hae In Yong

https://orcid.org/0000-0003-0970-4496

Seok-Hyeon Beak

https://orcid.org/0000-0003-4550-5937

Hyun Jin Kim

https://orcid.org/0000-0003-1289-7292

Cheorun Jo

https://orcid.org/0000-0003-2109-3798

Komang Gede Wiryawan

https://orcid.org/0000-0002-0593-9653

Myunggi Baik

https://orcid.org/0000-0001-8373-9772

Submitted Jan 18, 2018; Revised Apr 11, 2018 Accepted Jun 29, 2018
Objective: This study was performed to compare fat content, reducing sugar contents, sensory traits, and fatty acid (FA) and volatile compound profiles in longissimus thoracis (LT) among Korean cattle (KC), Holstein (HO), and Angus (AN) steers.

Methods: Twelve LT samples (about $500 \mathrm{~g}$ each) of KC with an average age of $31 \pm 0.42$ months, an average carcass weight of $431 \pm 12.5 \mathrm{~kg}$, and a quality grade (QG) of $1+$ were obtained from the joint livestock products market. Twelve LT samples of $\mathrm{HO}$ cattle with an average age of $24 \pm 0.54$ months, an average carcass weight of $402 \pm 7.81 \mathrm{~kg}$, and a QG of 2 were also obtained from the same market. Twelve LT samples of AN steers with an average age of about 20 months and a QG of choice were purchased from a beef delivery company. After slaughter, samples were kept at $4^{\circ} \mathrm{C}$ for 42 days and prepared for immediate analysis or stored at appropriate conditions. The chemical composition, color, $\mathrm{pH}$, shear force, collagen content, reducing sugars, sensory evaluation, FA composition, and volatile compound content for each LT sample were analyzed.

Results: The LT of KC had the highest $(\mathrm{p}<0.05)$ fat content, the highest reducing sugar content, and the highest scores in the sensory evaluation (flavor, tenderness, juiciness, and overall acceptance). All the sensory traits were positively correlated $(\mathrm{p}<0.001)$ with intramuscular fat and reducing sugar content. Several FAs and volatile compound profiles varied among the breeds. KC LT had the highest $(\mathrm{p}<0.05)$ concentrations of acetaldehyde, 3-methyl butanal, and 3-hydroxy-2-butanone, and these volatile compounds were positively correlated $(\mathrm{p}<0.05)$ with all the sensory traits.

Conclusion: Variations in fat content and reducing sugar contents and FA and volatile compound profiles may contribute to differences in the sensory quality of LT among breeds.

Keywords: Korean Cattle; Longissimus thoracis; Reducing Sugar Content; Sensory Trait; Fatty Acids; Volatile Compounds

\section{INTRODUCTION}

Per capita beef consumption in South Korea has increased nearly four-fold, from $2.6 \mathrm{~kg}$ in 1980 to $10.8 \mathrm{~kg}$ in 2014; this is likely a result of increasing levels of income and the westernization of Korean eating patterns [1]. Domestic beef production in South Korea is primarily based on Korean cattle (KC), but Holstein (HO) steers are also produced [2]. The self-sufficiency rate of beef consumption in South Korea has decreased and reached as low as 37.7\% in 2016 [3]. South Korea's main beef importers in 2016 were the United States and Australia, both of which predominantly imported Angus (AN) cattle [3]. Korean consumers have historically preferred $\mathrm{KC}$ beef to domestic $\mathrm{HO}$ and imported beef because they believe that the 
palatability (e.g., flavor, juiciness, and tenderness) of KC beef is superior to that of $\mathrm{HO}$ and imported beef [4]. Limited information is available on the factors that affect the preference of Korean consumers for KC beef over other breeds.

Beef flavor, juiciness, and tenderness are key factors in evaluation of meat palatability, and these three factors in combination are known to have great influence on consumers' overall perceptions of the taste of beef [5]. Intramuscular fat (IMF) or fat content are closely related to both beef flavor and tenderness [6]. In addition to IMF contents, the composition and content of fatty acids (FAs) are also important factors in beef palatability [7]. It has been suggested that oleic acid (C18:1n9) is positively associated with beef flavor, whereas polyunsaturated fatty acid (PUFA) may be negatively associated with beef flavor [8].

During the cooking process of meat, large quantities of volatile compounds are formed, such as aldehydes, ketones, hydrocarbons, furans, thiazoles, and pyrazines; these compounds directly affect flavor $[9,10]$. Volatile compounds can form via several pathways, including a Maillard reaction of amino acids or peptides with reducing sugars (e.g., glucose and ribose), thermal lipid degradation, and the interaction between Maillard reaction products and lipid oxidation products $[11,12]$. Of these pathways, thermal lipid oxidation is primarily involved in the formation of major volatile compounds, and FA oxidation is primarily responsible for the development of flavor [13]. Therefore, different types or amounts of FAs may influence the generation of volatile compounds, the development of aroma characteristics, and the intensity of flavor upon thermal processing.

Reducing sugars, such as glucose and ribose, have been reported to contribute to improved flavor of cooked meat by reacting with amino acids to produce many important volatile compounds via Maillard reactions [14]. Currently, little information is available on the reducing sugar content of beef and its association with sensory traits. Furthermore, limited information is available regarding differences in reducing sugar content, sensory traits, and FA and volatile compound profiles among cattle breeds. This study was performed to compare the physico-chemical characteristics, reducing sugar content, sensory traits, and FA and volatile compound profiles of the longissimus thoracis (LT) among $\mathrm{KC}, \mathrm{HO}$, and imported AN breeds, and to identify correlations among these parameters.

\section{MATERIALS AND METHODS}

\section{Beef sample preparation}

The KC steers were from 12 female cows (implanted with the semen of seven different bulls), and were raised according to conventional Korean feeding methods. The HO steers were from 12 female cows (implanted with the semen of 11 different bulls), and were also raised according to conventional Korean feeding methods. Briefly, the KC male calves were weaned at 3 months of age and were then fed roughage (70\%) and concentrate (30\%) until 5 months of age. The calves were castrated at 6 months of age, and steers were grown in pens using group feeding. The steers were fed concentrate and roughage separately until slaughter at around 29 months of age. During growing stage (6 to 14 months of age), steers were fed a concentrate diet (1.6\% of body weight [BW]/steer) and a timothy hay (approximately $0.75 \%$ of BW/steer). During fattening stage (early fattening, 15 to 23 months of age; late fattening, 24 to 29 months of age), steers were fed a concentrate diet (approximately $1.5 \%$ of BW/steer) and rice straw (1 kg/steer). The HO male calves were weaned at two months of age, then fed starter $\operatorname{diet}(30 \%)$ and hay (70\%) until four months of age, and were castrated at 5 months of age. The steers were fed concentrate and roughage separately until slaughter at around 20 months of age. During growing stage (5 to 8 months of age), steers were fed a concentrate diet (approximately $2.4 \%$ of BW/steer) and a timothy hay (approximately $0.75 \%$ of BW/steer). During fattening stage (early fattening, 9 to 13 months of age; late fattening, 14 to 20 months of age), steers were fed a concentrate diet (approximately $1.8 \%$ of BW/steer) and rice straw $(1 \mathrm{~kg} / \mathrm{steer})$. Cattle were slaughtered in a local municipal slaughterhouse (Bucheon, Republic of Korea). Carcass traits were evaluated by a meat grader using the Korean carcass-grading system of the Korean Institute for Animal Products Quality Evaluation [15] at $24 \mathrm{~h}$ post mortem. The LT samples (about $500 \mathrm{~g}$ each) of KC with an average age of $31 \pm 0.42$ months, an average carcass weight of $431 \pm 12.5 \mathrm{~kg}$, and a quality grade (QG) of 1+ were obtained from the joint livestock products market (Bucheon, Republic of Korea) immediately after grading. The LT samples of $\mathrm{HO}$ cattle with an average age of $24 \pm 0.54$ months, an average carcass weight of $402 \pm 7.81 \mathrm{~kg}$, and a QG of 2 were also obtained from the same market. Samples were then vacuum-packaged, transported under ice to a laboratory, and stored at $4^{\circ} \mathrm{C}$ for 42 days until the analysis. We selected a QG of $1+$ for KC beef because the largest proportion (44.4\%) of KC steer beef was of this grade [16]. Similarly, a QG of 2 for $\mathrm{HO}$ beef was selected because the largest proportion (48.6\%) of HO steer beef was of this grade. The LT samples of the AN steers (choice grade) had an average age of about 20 months; they were slaughtered on the same day as the $\mathrm{KC}$ and $\mathrm{HO}$ cattle in the United States, shipped at $4^{\circ} \mathrm{C}$, and imported by a beef delivery company (A-Meat Corp., Seoul, Republic of Korea). It took approximately five weeks to obtain AN samples from USA. Aging is one of significant factors affecting meat characteristics. Thus, samples of $\mathrm{KC}$ and $\mathrm{HO}$ samples also stored $42 \mathrm{~d}$ to give same storage time to avoid aging variation among three breeds. The choice grade of the 12 AN LT samples was randomly purchased from approximately 100 choice beef options. We selected a choice grade because it is the most 
popular and abundant grade in the United States. The AN cattle were raised using a conventional beef production system in the United States. After 42 days of storage, the packages containing the LT samples of the different breeds were opened and the external fat was trimmed away. The LT samples were minced using a mini chopper (CH180; Kenwood, Shanghai, China) for $30 \mathrm{~s}$. Minced LT samples from various locations were pooled and stored at $-70^{\circ} \mathrm{C}$ for analysis of the chemical composition, and collagen, reducing sugar, FA, and volatile compound contents. Samples assessed for shear force and sensory traits were collected but not minced. Some samples were used immediately for shear force evaluation, while others were stored at $-70^{\circ} \mathrm{C}$ for the sensory evaluation.

\section{Proximate composition, color, $\mathrm{pH}$, shear force, and collagen content}

Moisture, crude protein, and crude fat contents were analyzed according to the methods of the Association of Official Analytical Chemists (AOAC) [17]. Surface-color values (International Commission on Illumination [CIE]; $L^{\star}, a^{*}$, and $b^{*}$ values represent lightness, redness, and yellowness, respectively) were measured using a colorimeter (CR-310; Minolta Co., Ltd., Osa$\mathrm{ka}$, Japan). The $\mathrm{pH}$ of each sample was measured as described previously [18]. The samples (1 g) used for $\mathrm{pH}$ measurement were homogenized with distilled water $(9 \mathrm{~mL})$ at Lv.6 (30,000 rpm) for $30 \mathrm{~s}$ (T10 Basic; Ika Works, Staufen, Germany) and centrifuged at 2,265 $\times$ g for $10 \mathrm{~min}$ (Continent 512R; Hanil Co., Ltd., Incheon, Korea). The sample $\mathrm{pH}$ was measured with a pH meter (SevenGo; Mettler-Toledo, Inc., Schwerzenbach, Switzerland). The shear force (N) was measured as described previously [18] using a Warner-Bratzler shear attached to a texture analyzer (CT3 10K; Brookfield Engineering Laboratories, Middleboro, MA, USA), based on slight modifications of the method developed by Kim et al [19].

The total insoluble collagen content was measured using a spectrophotometer, as described previously [18], according to a modified method of [20].

\section{Reducing sugars}

Sugars were extracted from LT sample (1 $\mathrm{g}$ ) by homogenization (T10 Basic; Ika Works, Germany) with $5 \mathrm{~mL}$ of $80 \%$ ethanol $\left(50^{\circ} \mathrm{C}\right.$ ) and were centrifuged at 2,265 $\times \mathrm{g}$ for $10 \mathrm{~min}$ (Continent 512; Hanil Co., Ltd., Korea). The extracts were then centrifuged (Continent 512R; Hanil Co., Ltd., Korea) at 2,265×g for $10 \mathrm{~min}$. The resulting supernatants were filtered (filter paper No.1; Whatman International Ltd., Springfield Mill, Kent, England) separately into $15-\mathrm{mL}$ tubes and evaporated using $\mathrm{N}_{2}$ gas (99.999\%). Next, distilled water $(2 \mathrm{~mL}$ ) was added to each tube and vortexed to dissolve the sugars. The mixture was transferred to a $2-\mathrm{mL}$ microtube and centrifuged at $18,500 \times \mathrm{g}$ for 10 min (HM-150IV; Hanil Co., Ltd., Korea). The reducing sugar content was measured using a dinitrosalicylic (DNS) acid method, as described by the [21]. In brief, $1 \mathrm{~mL}$ of each extract was mixed with $2 \mathrm{~mL}$ of the DNS solution $(0.5 \mathrm{~g}$ of DNS acid, $8.0 \mathrm{~g}$ of sodium hydroxide, and $150 \mathrm{~g}$ of Rochelle salt in $500 \mathrm{~mL}$ of distilled water) in a $15-\mathrm{mL}$ test tube and heated in a water bath $\left(90^{\circ} \mathrm{C}\right)$ for $10 \mathrm{~min}$. The mixture was then cooled under running water for $5 \mathrm{~min}$ and the absorbance was measured at $550 \mathrm{~nm}$ using a spectrophotometer (X-ma 3100; Human Co., Ltd., Seoul, Korea). The reducing sugar content was calculated using a standard curve developed with glucose (Sigma Corp., St. Louis, MO, USA).

\section{Sensory evaluation}

We used similar size $\left(15 \times 40 \times 15 \mathrm{~mm}^{3}\right)$ of LT samples to have a uniform cooking from outside and inside of meat flesh, and the samples were cooked. The internal temperature of the samples was monitored using a digital thermometer (YF-160A Type-K; YFE, Hsinchu City, Taiwan) that was placed in the center or each edge of the grill; the samples were removed from the electronic grill (EG-GW1700, Kitchenart, Incheon, Korea) after they reached an internal temperature of $72^{\circ} \mathrm{C}$. Ten untrained panelists evaluated the cooked samples for appearance, odor, taste, flavor, tenderness, juiciness, and overall acceptability. A 9-point hedonic scale, where 9 indicated extremely liked and 1 indicated extremely disliked, was employed to evaluate all of the parameters. For the evaluation, samples were placed into randomly coded white dishes and served together with drinking water to rinse the panelists' oral cavities, following a test of each sample. The sensory characteristics were evaluated in three independent experiments.

\section{Fatty acid composition}

The FA composition was measured as described previously [22]. Briefly, lipids in beef samples $(5 \mathrm{~g})$ were extracted with chloroform/methanol $(100 \mathrm{~mL})$ according to the procedure of [23]. Extracted lipids were methylated with $\mathrm{BF}_{3}$-methanol $(14 \%, \mathrm{w} / \mathrm{w})$, and FA methyl esters (FAMEs) were injected into a gas chromatograph (HP 7890; Agilent Technologies, Santa Clara, CA, USA). A split inlet (split ratio, 50:1) was used to inject the samples into a capillary column (SP 2560 Capillary column; $100 \mathrm{~m} \times 0.25 \mathrm{~mm} \times 0.20 \mu \mathrm{m}$ film thickness). The inlet temperature was $210^{\circ} \mathrm{C} . \mathrm{N}_{2}$ served as the carrier gas, at a constant flow rate of $1 \mathrm{~mL} / \mathrm{min}$. The column oven temperatures were as follows: $100^{\circ} \mathrm{C}$ for $5 \mathrm{~min}$, increased to $240^{\circ} \mathrm{C}$ at $4^{\circ} \mathrm{C} /$ min, then held at $240^{\circ} \mathrm{C}$ for $20 \mathrm{~min}$. Individual FAMEs were identified by comparison of the relative retention times of the peaks from the samples with those of the standard mixture (37-component FAME Mix; Supelco, Bellefonte, PA, USA). The FA composition of the fat was calculated based on the peak area. Relative quantities were expressed as weight percent of total FAs.

FA content (values per $100 \mathrm{~g}$ of beef) is also important to measure, and was obtained by using FA percentage in LT fat 
and fat content in LT as previously described [22]. Individual FA content ( $\mathrm{g} / 100 \mathrm{~g}$ meat) was calculated as follows:

$$
\begin{aligned}
& \text { Individual FA content }(\mathrm{g} \mathrm{FA} / 100 \mathrm{~g} \text { meat }) \\
& =\text { crude fat content }(\mathrm{g} \text { fat } / 100 \mathrm{~g} \text { meat }) \\
& \quad \times \text { individual FA percentage }(\%) \times 0.953(\mathrm{~g} \mathrm{FA} / \mathrm{g} \text { fat })
\end{aligned}
$$

\section{Volatile compounds}

To analyze the volatile compounds, samples were minced and grilled on a hot plate (PC-420D; Corning, Corning, NY, USA) until they reached an internal temperature of $72^{\circ} \mathrm{C}$. Then, the sample ( $10 \mathrm{~g})$ was immediately transferred to individually labeled $20 \mathrm{~mL}$ clear glass vials (N9306078; PerkinElmer, Boston, MA, USA) and closed with a polytetrafluoroethylene septa and screw cap. One minute later, the vials were placed in the oven of a headspace sampler, and extraction of the volatile compounds of the samples was performed using a headspace autosampler. The transfer line from the headspace sampler was directly connected to the injector for the gas chromatography (GC).

A PerkinElmer 680 GC equipped with a $600 \mathrm{~T}$ mass spectrometry (MS) detector was used to analyze the volatile compounds. The compounds were separated using a HP-PLOT Q column (Agilent, Wilmington, DE, USA; $30 \mathrm{~m} \times 0.53 \mathrm{~mm} \times 0.25-\mu \mathrm{m}$ film thickness). The GC conditions were as follows: initial oven temperature, $35^{\circ} \mathrm{C}$; held for $5 \mathrm{~min}$, increased by $7^{\circ} \mathrm{C} / \mathrm{min}$ to $180^{\circ} \mathrm{C}$, held for $0.0 \mathrm{~min}$ at $180^{\circ} \mathrm{C}$, and then increased by $5^{\circ} \mathrm{C} /$ min to $250^{\circ} \mathrm{C}$ and held for $21 \mathrm{~min}$. The transfer line temperature was maintained at $250^{\circ} \mathrm{C}$. A mass spectrometer scanned from $\mathrm{m} / z 30$ to $\mathrm{m} / z 250$ with a $0.2 \mathrm{~s}$ cycle time. The ion source was set at $250^{\circ} \mathrm{C}$. Headspace was maintained at $85^{\circ} \mathrm{C}$ for 30 min and a ramped oven temperature was used $\left(50^{\circ} \mathrm{C}\right.$ for 3 min, increased by at $5^{\circ} \mathrm{C} / \mathrm{min}$ to $240^{\circ} \mathrm{C}$, and maintained for $9 \mathrm{~min}$ ). The inlet temperature was $210^{\circ} \mathrm{C}$. Helium served as the carrier gas, delivered at a constant flow rate of $20 \mathrm{~mL} / \mathrm{min}$. The resolved MS spectra obtained from the custom scripts were matched against reference mass spectra by using the National Institute of Standards and Technology (NIST) mass spectral search program for application to the NIST/US Environmental Protection Agency (EPA)/National Institutes of Health (NIH) mass spectral library (ver. 2.0). A GC chromatogram was used to quantify the volatile compounds, and MS was used to identify the volatile compounds. Results of the analyses are expressed as percentages of the total chromatographic area.

\section{Statistical analysis}

Data (12 animals/group) were analyzed by analysis of variance using the general linear model procedure (Proc GLM) of SAS software (SAS Institute, Cary, NC, USA). The LSMEANS PDIFF option was used to compare differences among mean values at $\mathrm{p}<0.05$. The CORR procedure of SAS was used to calculate Pearson's correlation coefficients.

\section{RESULTS AND DISCUSSION}

\section{Chemical composition, physico-chemical parameters,} collagen and reducing sugar contents, and sensory traits The chemical compositions, physico-chemical parameters, collagen and reducing sugar contents, and sensory traits of the LT of KC, HO, and AN breeds are shown in Table 1. The $\mathrm{KC}$ had the highest $(\mathrm{p}<0.05)$ fat content $(21.1 \%)$, followed by $\mathrm{HO}(7.08 \%)$ and $\mathrm{AN}(3.14 \%)$, whereas KC had the lowest $(\mathrm{p}<0.05)$ moisture and crude protein contents. This is consistent with previous study that reported higher $(\mathrm{p}<0.05)$ crude fat content in the loin of $\mathrm{KC}$ versus that of imported beef [24].

The LT of both KC and AN had similar CIE $a^{*}$ (redness) values, but the $\mathrm{LT}$ of $\mathrm{HO}$ had a lower $(\mathrm{p}<0.05)$ value than that of the two other breeds (Table 1). CIE $L^{*}$ - (lightness) and CIE $b^{*}$-value (yellowness) did not differ ( $>>0.05$ ) among the three breeds. Cho et al [24] also reported that the CIE $L^{\star}$ value of the loin did not differ among $\mathrm{KC}$ with a QG of $1+, \mathrm{KC}$ with a QG of 1, Australian AN, and crossbred breeds (AN and

Table 1. Chemical composition, physico-chemical parameter, collagen and

\begin{tabular}{|c|c|c|c|c|c|}
\hline Item & KC & $\mathrm{HO}$ & AN & SEM & $p$-value \\
\hline \multicolumn{6}{|l|}{ Chemical composition } \\
\hline Moisture (\%) & $57.6^{c}$ & $67.4^{b}$ & $73.7^{\mathrm{a}}$ & 0.99 & 0.001 \\
\hline Crude protein (\%) & $18.2^{b}$ & $22.1^{\mathrm{a}}$ & $21.5^{\mathrm{a}}$ & 0.28 & 0.001 \\
\hline Crude fat $(\%)$ & $21.1^{\mathrm{a}}$ & $7.08^{b}$ & $3.14^{c}$ & 1.14 & 0.001 \\
\hline \multicolumn{6}{|c|}{ Physico-chemical parameter } \\
\hline CIE $L^{*}$ & 45.8 & 45.3 & 45.4 & 0.27 & 0.82 \\
\hline $\mathrm{CIE} a^{*}$ & $17.0^{\mathrm{a}}$ & $16.1^{b}$ & $17.5^{\mathrm{a}}$ & 0.18 & 0.01 \\
\hline $\mathrm{CIE} b^{*}$ & 3.72 & 3.00 & 3.35 & 0.16 & 0.27 \\
\hline $\mathrm{pH}$ & $5.43^{b}$ & $5.19^{c}$ & $5.71^{\mathrm{a}}$ & 0.04 & 0.001 \\
\hline Shear force $(N)$ & $24.3^{c}$ & $32.0^{b}$ & $39.6^{\mathrm{a}}$ & 1.73 & 0.001 \\
\hline \multicolumn{6}{|l|}{ Collagen content } \\
\hline Total (mg/g) & 4.64 & 5.18 & 5.03 & 0.15 & 0.19 \\
\hline Soluble $(\mathrm{mg} / \mathrm{g})$ & $1.92^{b}$ & $1.91^{\mathrm{b}}$ & $2.46^{\mathrm{a}}$ & 0.11 & 0.03 \\
\hline Insoluble (mg/g) & $2.72^{b}$ & $3.27^{\mathrm{a}}$ & $2.57^{b}$ & 0.11 & 0.01 \\
\hline Reducing sugar (\%) & $0.42^{\mathrm{a}}$ & $0.18^{b}$ & $0.19^{b}$ & 0.02 & 0.001 \\
\hline \multicolumn{6}{|l|}{ Sensory traits ${ }^{11}$} \\
\hline Appearance & $5.90^{\mathrm{a}}$ & $5.70^{\mathrm{a}}$ & $5.33^{b}$ & 0.07 & 0.004 \\
\hline Odor & $6.23^{\mathrm{a}}$ & $4.70^{b}$ & $5.23^{b}$ & 0.14 & 0.001 \\
\hline Taste & $6.80^{\mathrm{a}}$ & $3.90^{b}$ & $4.47^{b}$ & 0.25 & 0.001 \\
\hline Flavor & $6.77^{\mathrm{a}}$ & $4.03^{b}$ & $4.60^{b}$ & 0.23 & 0.001 \\
\hline Tenderness & $6.73^{\mathrm{a}}$ & $5.23^{b}$ & $3.90^{c}$ & 0.22 & 0.001 \\
\hline Juiciness & $6.03^{\mathrm{a}}$ & $4.70^{b}$ & $3.97^{c}$ & 0.18 & 0.001 \\
\hline Overall acceptance & $6.83^{\mathrm{a}}$ & $4.23^{b}$ & $4.73^{b}$ & 0.23 & 0.001 \\
\hline
\end{tabular}
reducing sugar contents, and sensory traits in the longissimus thoracis from Korean cattle (KC), Holstein (HO), and Angus (AN) steers $(n=12)$

SEM, standard error of the mean; $\mathrm{CIE}$, International Commission on Illumination.

1) The score was evaluated with 10 semi-trained panelists (1, extremely dislike; 5 , neither dislike nor like; 9, extremely like).

a-c Means with different letters within the same row differ $(p<0.05)$. 
Hereford mix). Imported AN had the highest $(\mathrm{p}<0.05) \mathrm{pH}$, followed by $\mathrm{KC}$ and $\mathrm{HO}$.

The shear force of the LT was the lowest $(\mathrm{p}<0.05)$ in $\mathrm{KC}$, followed by $\mathrm{HO}$ and AN (Table 1). Shear force is known to be an indicator of meat tenderness. A previous study reported that tenderness increased with a decrease in shear force [25], and that shear force in turn decreased with an increase in QG [26]. In our study, the lowest shear force was seen in KC; this may be attributable to that meat having the highest fat content or IMF content. Total collagen content in the LT did not differ ( $>0.05$ ) among the three breeds (Table 1). Soluble collagen content was highest $(\mathrm{p}<0.05)$ in $\mathrm{AN}$, but did not differ between $\mathrm{KC}$ and $\mathrm{HO}$. Insoluble collagen content was highest $(\mathrm{p}<0.05)$ in $\mathrm{HO}$, and again did not differ between $\mathrm{KC}$ and $\mathrm{AN}$.

The reducing sugar content of the LT was highest $(\mathrm{p}<0.05)$ in $\mathrm{KC}(0.42 \%)$, and the content did not differ between $\mathrm{HO}$ $(0.18 \%)$ and AN $(0.19 \%)$ (Table 1$)$. Our study is the first to show that KC had the highest reducing sugar content among several breeds. Volatile flavor compounds mainly produce meat aromas and flavors during cooking. Maillard reactions between amino acids or peptides with reducing sugar are key processes in generating volatile compounds [27]. The reducing sugar for this reaction included ribose, glucose, glucose 6-phosphate, and ribose 5-phosphate [28]. It was reported that reducing sugar may act as important precursors of flavor in chicken meat [29]. Thus, the two-fold higher reducing sugar content in the LT from KC may influence the production of volatile compounds during cooking.

All sensory parameters, including flavor, tenderness, juiciness, and overall acceptance, were highest $(\mathrm{p}<0.05)$ in $\mathrm{KC}$, and no differences in flavor or overall acceptance were observed between $\mathrm{HO}$ and AN (Table 1). The IMF content positively affected the sensory quality $[6,18]$. The IMF is strongly correlated with fat content [18]. In our study, the LT of KC had a significantly higher fat content than that of the other two breeds, and the shear force of LT from KC was the lowest among the three breeds. Collectively, a higher fat content and lower shear force may have contributed to the higher sensory quality of the LT of KC compared with the other two breeds. Additionally, the reducing sugar content was highest in $\mathrm{KC}$, which may also in part contribute to the superior sensory traits of this breed, as discussed above.

\section{Percentages and contents of FA}

Of the 18 FAs identified in this study, the percentage of $\mathrm{C} 18: \ln 9$ was the highest, ranging from $39 \%$ to $44 \%$, followed by palmitic acid (C16:0) (26.5\% to 30\%) and stearic acid (C18:0) (11.4\% to $15.9 \%$ ) (Table 2). The percentages of $\mathrm{C} 16: 0$, palmitoleic acid $(\mathrm{C} 16: 1)$, and $\mathrm{C} 18: 1 \mathrm{n} 9$ were lowest $(\mathrm{p}<0.01)$ in $\mathrm{AN}$, and did not differ between $\mathrm{KC}$ and $\mathrm{HO}$. Cho et al [24] also reported higher proportions of $\mathrm{C} 16: 1$ and $\mathrm{C} 18: \ln 9$ in the loin fat of $\mathrm{KC}$ versus AN. The percentage of monounsaturated fatty
Table 2. Fatty acid composition (\% of fat) in the longissimus thoracis from Korean cattle (KC), Holstein (HO), and Angus (AN) steers ( $n=12)$

\begin{tabular}{|c|c|c|c|c|c|}
\hline Fatty acid & KC & HO & AN & SEM & $\mathrm{p}$-value \\
\hline $\mathrm{C} 12: 0$ & $0.11^{\mathrm{a}}$ & $0.11^{\mathrm{a}}$ & $0.00^{b}$ & 0.01 & 0.001 \\
\hline C13:0 & 0.04 & 0.06 & 0.10 & 0.01 & 0.14 \\
\hline C14:0 & $4.09^{a}$ & $3.90^{\mathrm{a}}$ & $3.02^{b}$ & 0.14 & 0.004 \\
\hline C14:1 & $1.39^{\mathrm{a}}$ & $1.36^{\mathrm{a}}$ & $0.68^{b}$ & 0.09 & 0.001 \\
\hline C15:0 & $0.23^{c}$ & $0.33^{b}$ & $0.50^{\mathrm{a}}$ & 0.02 & 0.001 \\
\hline C16:0 & $30.0^{\mathrm{a}}$ & $29.3^{\mathrm{a}}$ & $26.5^{b}$ & 0.36 & 0.001 \\
\hline C16:1 & $5.12^{\mathrm{a}}$ & $5.01^{\mathrm{a}}$ & $3.39^{b}$ & 0.19 & 0.001 \\
\hline C17:0 & $0.36^{c}$ & $0.92^{b}$ & $1.94^{\mathrm{a}}$ & 0.15 & 0.001 \\
\hline C17:1 & $0.50^{c}$ & $0.66^{b}$ & $1.12^{\mathrm{a}}$ & 0.05 & 0.001 \\
\hline C18:0 & $11.4^{b}$ & $12.4^{b}$ & $15.9^{\mathrm{a}}$ & 0.42 & 0.001 \\
\hline C18:1t & $0.22^{b}$ & $0.22^{b}$ & $0.42^{\mathrm{a}}$ & 0.03 & 0.002 \\
\hline C18:1n9 & $44.0^{\mathrm{a}}$ & $41.6^{\mathrm{a}}$ & $39.0^{b}$ & 0.54 & 0.001 \\
\hline C18:2 & $1.60^{b}$ & $2.55^{b}$ & $5.20^{\mathrm{a}}$ & 0.31 & 0.001 \\
\hline C18:3 & $0.04^{b}$ & $0.09^{b}$ & $0.19^{a}$ & 0.01 & 0.001 \\
\hline $\mathrm{C} 18: 2_{9 \mathrm{c} 11 \mathrm{t}}+\mathrm{C} 18: 2_{10 \mathrm{t} 12 \mathrm{c}}$ & 0.36 & 0.31 & 0.37 & 0.02 & 0.54 \\
\hline $\mathrm{C} 20: 1$ & $0.27^{\mathrm{a}}$ & $0.18^{b}$ & $0.22^{\mathrm{ab}}$ & 0.01 & 0.02 \\
\hline C20:3 & $0.14^{b}$ & $0.30^{\mathrm{a}}$ & $0.36^{\mathrm{a}}$ & 0.03 & 0.001 \\
\hline C20:4 & $0.17^{c}$ & $0.72^{b}$ & $1.04^{\mathrm{a}}$ & 0.08 & 0.001 \\
\hline SFA $^{1)}$ & 46.2 & 47.0 & 48.0 & 0.40 & 0.24 \\
\hline USFA $^{2)}$ & 53.8 & 53.0 & 52.0 & 0.40 & 0.25 \\
\hline MUFA $^{3)}$ & $51.5^{a}$ & $49.1^{a}$ & $44.9^{b}$ & 0.64 & 0.001 \\
\hline PUFA $^{4)}$ & $2.31^{c}$ & $3.97^{b}$ & $7.16^{\mathrm{a}}$ & 0.42 & 0.001 \\
\hline
\end{tabular}

SEM, standard error of the mean; SFA, saturated fatty acids; USFA, unsaturated fatty acids; MUFA, monounsaturated fatty acids; PUFA, polyunsaturated fatty acids.

1) $\mathrm{SFA}=\mathrm{C} 12: 0+\mathrm{C} 13: 0+\mathrm{C} 14: 0+\mathrm{C} 15: 0+\mathrm{C} 16: 0+\mathrm{C} 17: 0+\mathrm{C} 18: 0$.

2) USFA $=\mathrm{C} 14: 1+\mathrm{C} 16: 1+\mathrm{C} 17: 1+\mathrm{C} 18: 1 \mathrm{t}+\mathrm{C} 18: 1 \mathrm{C}+\mathrm{C} 20: 1$.

3) MUFA = C14:1+C16:1+C17:1+C18:1t+C18:1c+C20:1.

4) PUFA $=\mathrm{C} 18: 2+\mathrm{C} 18: 3+\mathrm{C} 20: 3+\mathrm{C} 20: 4+\mathrm{C} 18: 2_{9 \mathrm{c} 1 \mathrm{t}}+\mathrm{C} 18: 2_{10+12 \mathrm{c}}$.

${ }^{a-c}$ Means with different letters within the same row differ $(p<0.05)$.

acids (MUFAs) in the LT of KC and HO was higher $(\mathrm{p}<0.05)$ than that in AN beef. This may be because the proportion of $\mathrm{C} 18: \ln 9$ was higher in $\mathrm{KC}$ and $\mathrm{HO}$ than in AN. The MUFA deposition in the triacylglycerol fraction increased with increasing fat content, whereas PUFA was preferentially incorporated into the phospholipid fraction in the cell membranes [30]. Thus, the higher fat content of KC compared with AN may have contributed directly to the higher MUFA content of KC. The percentages of $\mathrm{C} 18: 0$, linoleic acid (C18:2), and arachidonic acid (C20:4) were lowest $(\mathrm{p}<0.01)$ in KC. The PUFA percentage of LT fat was lowest $(\mathrm{p}<0.01)$ in $\mathrm{KC}$ and highest in AN. Cho et al [24] also reported lower C18:2 and PUFA percentages for the longissimus muscle fat of $\mathrm{KC}$ versus AN. In addition, Jeong et al [31] reported that the longissimus lumborum of KC had lower C18:2 and PUFA percentages than that of HO. Hwang and Joo [8] reported that C18:1n9 was positively associated with beef flavor, whereas PUFAs were negatively associated with beef flavor. Taken together, variation in the proportions of these FAs may in part have contributed to differences in the sensory traits of the LT of different breeds.

Using the FA percentage and fat content of the LT, indivi- 
dual FA contents (g FA/100 g LT) were calculated based on a conversion factor (0.953; [32]). Among all FAs, the C18:1n9 content of the LT was the highest, ranging from 1.9 to 8.33 $\mathrm{g} / 100 \mathrm{~g}$ meat, followed by C16:0 (1.27 to $5.62 \mathrm{~g} / 100 \mathrm{~g}$ meat) and C18:0 (0.76 to $2.11 \mathrm{~g} / 100 \mathrm{~g}$ meat) (Supplementary Table S1). The content of most FAs in the LT, including C16:0, C16:1, $\mathrm{C} 18: 0$, and $\mathrm{C} 18: 1 \mathrm{n} 9$, were highest $(\mathrm{p}<0.001)$ in $\mathrm{KC}$ and lowest $(\mathrm{p}<0.001)$ in AN. These results are likely attributable to the fat content in the LT being highest in KC and lowest in AN.

\section{Volatile compounds}

A total of 31 volatile compounds, including aldehydes, hydrocarbons, ketones, pyrazines, alcohols, and terpenes, were detected in the LT of the three cattle breeds (Table 3). The abundant volatile compounds, accounting for $7.28 \%$ to $60 \%$ of the total volatile compounds, included acetaldehyde and 2 -propanone. The moderate compounds, accounting for $1.26 \%$ to $25.9 \%$ of the total volatile compounds, included 2-methyl butanal, hexanal, and methanethiol. The minor compounds, accounting for $0.01 \%$ to $8.5 \%$ of the total volatile compounds, included propanal, butanal, 3-methyl butanal, pentanal, heptanal, benzaldehyde, octanal, nonanal, butane, carbon disulfide, 2-butene, n-pentane, hexane, heptane, octane, ethylacetate, 2-butanone, 2,3-butanedione, 3-hydroxy-2-butanone, 2-heptanone, 2,3-octanedione, dimethyl sulfide, ethanol, isopropyl alcohol, 1-pentanol, and 1,3,5-cycloheptatriene.

The percentages of produced aldehydes varied among the three breeds. Acetaldehyde and 3-methyl butanal contents were highest $(\mathrm{p}<0.05)$ in $\mathrm{KC}$, followed by $\mathrm{HO}$ and $\mathrm{AN}$ (Table 3). The 2-methyl butanal content was similar between $\mathrm{KC}$ and $\mathrm{HO}$, and was lowest in AN. In contrast, propanal, pentanal, hexanal, heptanal, and octanal contents were highest $(\mathrm{p}<0.05)$ in $\mathrm{AN}$, and similar between $\mathrm{KC}$ and HO. During the formation of volatile compounds, Strecker degradation is one of the most important reactions related to the generation of the precursors of thermal formation aromas. The Strecker aldehydes acetaldehyde (sharp, penetrating, fruity), 2-methyl propanal (penetrating, green), 3-methyl butanal (malty, green), and 2-methyl butanal (ethereal, bitter, almond, green), which are well-known volatile components of cooked beef, may be derived from alanine, valine, leucine, and isoleucine, respectively [33]. Of these aldehydes, acetaldehyde is associated with many reactions that may explain the formation of meaty aromas: 3,5-dimethyl-1,2,4-trithiolane, trithioacetaldehyde, thialdine, 2,4-dimethylthiazole, 2,4-dimethyl-5-ethylthiazole, and 2,4,5trimethyl-3-thiazoline together appear to impart a complex meat flavor during cooking. Acetaldehyde provides the carbon skeleton on their structures [33]. In addition, cysteine is also a well-known precursor of meat flavor. Some compounds, including mercaptoacetaldehyde, hydrogen sulfide, and acetaldehyde, were identified as common products when cysteine was boiled with various carbonyl compounds. Of these com-
Table 3. Volatile compounds (\%) in the longissimus thoracis from Korean cattle $(\mathrm{KC})$, Holstein (HO), and Angus (AN) steers $(n=12)$

\begin{tabular}{|c|c|c|c|c|c|}
\hline Volatile compound & KC & $\mathrm{HO}$ & AN & SEM & $p$-value \\
\hline \multicolumn{6}{|l|}{ Aldehyde } \\
\hline Acetaldehyde & $60.0^{\mathrm{a}}$ & $49.1^{b}$ & $31.5^{c}$ & 2.43 & 0.001 \\
\hline Propanal & $0.29^{b}$ & $0.53^{b}$ & $2.48^{\mathrm{a}}$ & 0.19 & 0.001 \\
\hline Butanal & $0.06^{b}$ & $1.17^{\mathrm{a}}$ & $0.33^{\mathrm{ab}}$ & 0.22 & 0.1 \\
\hline 2-Methyl butanal & $2.79^{\mathrm{a}}$ & $2.76^{\mathrm{a}}$ & $1.26^{\mathrm{b}}$ & 0.13 & 0.001 \\
\hline 3-Methyl butanal & $1.25^{\mathrm{a}}$ & $0.98^{b}$ & $0.54^{c}$ & 0.06 & 0.001 \\
\hline Pentanal & $0.81^{b}$ & $1.56^{b}$ & $8.50^{\mathrm{a}}$ & 0.66 & 0.001 \\
\hline Hexanal & $1.76^{\mathrm{b}}$ & $3.81^{b}$ & $25.9^{\mathrm{a}}$ & 2.07 & 0.001 \\
\hline Heptanal & $0.07^{b}$ & $0.14^{b}$ & $0.92^{\mathrm{a}}$ & 0.08 & 0.001 \\
\hline Benzaldehyde & $0.24^{\mathrm{a}}$ & $0.29^{\mathrm{a}}$ & $0.17^{\mathrm{b}}$ & 0.01 & 0.004 \\
\hline Octanal & $0.05^{b}$ & $0.09^{b}$ & $0.58^{\mathrm{a}}$ & 0.04 & 0.001 \\
\hline Nonanal & 0.02 & 0.01 & 0.01 & 0.00 & 0.79 \\
\hline \multicolumn{6}{|l|}{ Hydrocarbon } \\
\hline Methanethiol & $8.89^{b}$ & $12.8^{\mathrm{a}}$ & $3.98^{c}$ & 0.75 & 0.001 \\
\hline Butane & $0.94^{b}$ & $1.08^{\mathrm{a}}$ & $1.12^{\mathrm{a}}$ & 0.03 & 0.02 \\
\hline Carbon disulfide & 1.77 & 2.01 & 0.96 & 0.20 & 0.13 \\
\hline 2-Butene & $0.29^{b}$ & $0.36^{\mathrm{a}}$ & $0.30^{b}$ & 0.01 & 0.02 \\
\hline n-Pentane & $0.73^{b}$ & $1.70^{b}$ & $6.47^{\mathrm{a}}$ & 0.49 & 0.001 \\
\hline Hexane & $0.41^{b}$ & $0.83^{\mathrm{a}}$ & $0.65^{\mathrm{ab}}$ & 0.06 & 0.01 \\
\hline Heptane & $0.05^{b}$ & $0.06^{b}$ & $0.53^{\mathrm{a}}$ & 0.04 & 0.001 \\
\hline Octane & 0.45 & 1.56 & 1.30 & 0.48 & 0.63 \\
\hline Ethylacetate & $0.32^{b}$ & $1.27^{\mathrm{a}}$ & $0.62^{a b}$ & 0.17 & 0.1 \\
\hline \multicolumn{6}{|l|}{ Ketone } \\
\hline 2-Propanone & $14.8^{\mathrm{a}}$ & $13.9^{\mathrm{a}}$ & $7.28^{b}$ & 0.68 & 0.001 \\
\hline 2-Butanone & $0.96^{b}$ & $1.49^{\mathrm{a}}$ & $0.38^{c}$ & 0.11 & 0.001 \\
\hline 2,3-Butanedione & $0.08^{\mathrm{a}}$ & $0.04^{b}$ & $0.03^{b}$ & 0.00 & 0.001 \\
\hline 3-Hydroxy-2-butanone & $0.89^{\mathrm{a}}$ & $0.14^{b}$ & $0.17^{b}$ & 0.08 & 0.001 \\
\hline 2-Heptanone & $0.04^{b}$ & $0.05^{b}$ & $0.24^{\mathrm{a}}$ & 0.02 & 0.001 \\
\hline 2,3-Octanedione & $0.05^{b}$ & $0.14^{b}$ & $1.01^{\mathrm{a}}$ & 0.09 & 0.001 \\
\hline \multicolumn{6}{|l|}{ Pyrazine } \\
\hline Dimethyl sulfide & 0.48 & 0.53 & 0.65 & 0.05 & 0.29 \\
\hline \multicolumn{6}{|l|}{ Alcohol } \\
\hline Ethanol & 1.07 & 0.88 & 0.45 & 0.18 & 0.35 \\
\hline Isopropyl alcohol & $0.26^{b}$ & $0.49^{\mathrm{a}}$ & $0.24^{b}$ & 0.03 & 0.001 \\
\hline 1-Pentanol & $0.06^{b}$ & $0.08^{b}$ & $0.72^{\mathrm{a}}$ & 0.06 & 0.001 \\
\hline \multicolumn{6}{|l|}{ Terpene } \\
\hline 1,3,5-Cycloheptatriene & $0.18^{b}$ & $0.22^{b}$ & $0.66^{\mathrm{a}}$ & 0.05 & 0.001 \\
\hline
\end{tabular}

pounds, acetaldehyde is produced by Strecker degradation or cysteine hydrolysis [34]. Acetaldehyde was the most abundant volatile compound detected in this study. Among the three cattle breeds, the acetaldehyde content was significantly higher in $\mathrm{KC}$ than in $\mathrm{HO}$ and $\mathrm{AN}$, and there was a positive correlation between acetaldehyde content and sensory scores. The reducing sugar content was also significantly higher in $\mathrm{KC}$, which may in part be due to the relatively high content of sugars in this type of beef; reducing sugar is a substrate in Maillard reactions or complex Maillard and Strecker reactions [35]. Thus, higher percentages of acetaldehydes may in part have contributed to the higher sensory scores of KC beef. 
Hydrocarbon percentages varied among the three breeds. The methanethiol percentage in the LT was highest $(\mathrm{p}<0.01)$ in $\mathrm{HO}$, and lowest in AN. Butane, hexane, and ethylacetate were present in similar proportions in $\mathrm{HO}$ and $\mathrm{AN}$, while $\mathrm{KC}$ had a lower butane percentage $(\mathrm{p}<0.05)$ than that of the other two breeds. The percentages of $\mathrm{n}$-pentane and heptane were highest $(\mathrm{p}<0.01)$ in $\mathrm{AN}$, while the $\mathrm{KC}$ and $\mathrm{HO}$ breeds had similar percentages of these compounds. Carbon disulfide and octane percentages did not differ ( $p>0.05)$ among the three breeds. Hydrocarbons are derived from lipid thermal oxidation, which is a reaction catalyzed by heme compounds such as myoglobin and hemoglobin [36]. Although hydrocarbon components make up a certain proportion of volatile compounds, Min et al [37] reported that both saturated and unsaturated hydrocarbons play a minor role in the flavor of roast beef, as they contain relatively weak, non-beef-like odors. In this study, the correlations between flavor and the percentages of most hydrocarbons, including butane, carbon disulfide, 2-butene, n-pentane, hexane, heptane, octane, and ethylacetate were not significant (data not shown). Collectively, hydrocarbon variation among the three breeds did not seem to significantly affect the flavor of LT.

Among the ketones, 2-propanone percentages were similar in both KC and HO LT, and lowest $(\mathrm{p}<0.01)$ in AN LT. The percentage of 2-butanone was highest $(\mathrm{p}<0.01)$ in HO LT, and lowest in AN LT. Both 2,3-butanedione and 3-hydroxy-2-butanone percentages were highest $(\mathrm{p}<0.01)$ in $\mathrm{KC}$, while $\mathrm{HO}$ and AN had similar percentages of these compounds. Both 2-heptanone and 2,3-octanedione percentages were highest $(\mathrm{p}<0.01)$ in $\mathrm{AN}$, while $\mathrm{KC}$ and $\mathrm{HO}$ had similar contents of these compounds. Previous reports have shown that 2,3-butanedione and 3-hydroxy-2-butanone contents in AN were higher in prime grades compared with choice or standard grades [38]. Ketones are also related to fat content, and ketone content increases with increasing fat content [39].

\section{Correlation}

We analyzed Pearson correlation coefficients for the chemical composition, physical-chemical parameters, and sensory traits of pooled LTs from KC, HO, and AN (Supplementary Table S2). Fat content was one of the factors most strongly associated with sensory traits (flavor, tenderness, juiciness, and overall acceptance); these results were consistent with our previous study that showed positive correlations between fat content and sensory traits (juiciness and overall acceptance) [18].

Little information about the correlation between beef carcass characteristics and reducing sugar content is available. In this study, we analyzed Pearson correlation coefficients for chemical composition and sensory traits with the reducing sugar content of pooled LTs from the three breeds. The reducing sugar content in the LT was positively correlated $(0.63 \leq \mathrm{r} \leq 0.71$;
Table 4. Pearson correlation coefficients of chemical composition and sensory traits with reducing sugar contents of pooled longissimus thoracis from Korean cattle (KC), Holstein (HO), and Angus (AN) steers ( $n=36$ )

\begin{tabular}{lc}
\hline Item & Reducing sugar content \\
\hline Chemical composition & $-0.70^{* * *}$ \\
Moisture & $-0.72^{* * *}$ \\
Crude protein & $0.71^{* * *}$ \\
Crude fat & \\
Sensory traits & $0.63^{* * *}$ \\
Flavor & $0.59^{* * *}$ \\
Tenderness & $0.55^{* * *}$ \\
Juiciness & $0.63^{* * *}$ \\
Overall acceptance &
\end{tabular}

*** $p<0.001$

$\mathrm{p}<0.001$ ) with fat content and sensory traits (flavor and overall acceptance) (Table 4). We also found that KC LT had the highest reducing sugar content and the best sensory traits among the three breeds. As mentioned above, reducing sugar, especially glucose, can contribute to an improved meat flavor by reacting with amino acids to produce important volatile compounds via Maillard reactions [35]. Our study thus implies that higher reducing sugar content may positively affect flavor and overall acceptance.

Crude fat content was positively correlated with C14:0, C16:0 (0.48 $\leq \mathrm{r} \leq 0.50, \mathrm{p}<0.01), \mathrm{C} 16: 1, \mathrm{C} 18: 1 \mathrm{n} 9$, and MUFA percentages $(0.53 \leq \mathrm{r} \leq 0.73, \mathrm{p}<0.001)$, and negatively correlated with C18:0, C18:2, and PUFA percentages $(-0.75 \leq r \leq-0.71$, $\mathrm{p}<0.001$ ), in the LT fat (Supplementary Table S3). This is generally consistent with our previous study [22] that showed positive correlations of $\mathrm{C} 18: \ln 9$ and MUFA percentages, and negative correlations of $\mathrm{C} 18: 2$ and PUFA percentages, with LT fat content.

Sensory traits, including flavor, tenderness, and juiciness, were positively correlated $(0.35 \leq \mathrm{r} \leq 0.61, \mathrm{p}<0.05)$ with $\mathrm{C} 16: 0$, C18:1n9, and MUFA percentages in LT fat, and negatively correlated $(-0.70 \leq \mathrm{r} \leq-0.42, \mathrm{p}<0.05)$ with $\mathrm{C} 18: 2$ and PUFA percentages (Table 5). Mandell et al [40] reported that C18:1n9 might be positively associated with beef flavor, whereas PUFA might be negatively associated with beef flavor. Other studies have also shown that $\mathrm{C} 18: 1 \mathrm{n} 9$ is positively associated with beef flavor, whereas C18:2 is negatively associated with beef flavor [41]. O'Quinn [42] reported that MUFAs, such as lauric acid (C12:1), myristic acid (C14:1), C16:1, and C18:1n9, were all positively correlated with overall flavor desirability (beefy, browned/grilled, brothy, buttery, and sweet flavors), and negatively correlated with bloody/metallic, grassy, gamey, livery, fishy, and sour flavor intensities, which can impart bad flavor to the beef. Collectively, C18:1n9, and MUFA percentages may positively affect sensory traits, whereas C18:2 and PUFA percentages may negatively affect sensory traits. In this study, we found that C18:1n9 and MUFA percentages were highest, and 
Table 5. Pearson correlation coefficients of sensory traits with fatty acid composition (\% of fat) of pooled longissimus thoracis from Korean cattle (KC), Holstein (HO), and Angus (AN) steers $(n=36)$

\begin{tabular}{lllllllllll}
\hline Item & C14:0 & C16:0 & C16:1 & C18:0 & C18:1n9 & C18:2 & SFA & USFA & MUFA & PUFA \\
\hline Flavor & 0.24 & $0.35^{*}$ & 0.21 & -0.30 & $0.35^{*}$ & $-0.42^{*}$ & -0.07 & 0.07 & $0.35^{*}$ & $-0.46^{* *}$ \\
Tenderness & $0.43^{* *}$ & $0.61^{* * *}$ & $0.49^{* *}$ & $-0.58^{* * *}$ & $0.53^{* * *}$ & $-0.70^{* * *}$ & -0.18 & 0.18 & $0.57^{* * *}$ & $-0.70^{* * *}$ \\
Juiciness & 0.32 & $0.50^{* *}$ & $0.37^{*}$ & $-0.50^{* *}$ & $0.51^{* *}$ & $-0.59^{* * *}$ & -0.21 & 0.20 & $0.52^{* * *}$ & $-0.60^{* * *}$ \\
Overall acceptance & 0.26 & $0.37^{*}$ & 0.24 & -0.30 & 0.32 & $-0.43^{* *}$ & -0.03 & 0.03 & 0.33 & $-0.47^{* *}$ \\
\hline
\end{tabular}

SFA, saturated fatty acids; USFA, unsaturated fatty acids; MUFA, monounsaturated fatty acids; PUFA, polyunsaturated fatty acids.

${ }^{*} p<0.05 ;{ }^{* *} p<0.01 ;{ }^{* *} p<0.001$.

C18:2 and PUFA percentages were lowest, in KC LT fat among the three breeds. Taken together, the high percentages of C18:1n9 and MUFA, and low percentages of C18:2 and n-6 PUFA, in KC LT fat may contribute to the sensory traits of $\mathrm{KC}$ beef being rated as the best for Korean consumers.

We analyzed the correlation coefficients for chemical composition, physico-chemical parameters, reducing sugar content, and sensory traits with the volatile compound content of pooled LTs from KC, HO, and AN. Both the crude fat $(0.63 \leq r \leq 0.70$, $\mathrm{p}<0.001)$ and reducing sugar contents $(0.39 \leq \mathrm{r} \leq 0.57, \mathrm{p}<0.05)$ were positively correlated with several volatile compounds, including acetaldehyde, 3-methyl butanal, 2,3-butanedione, and 3-hydroxy-2-butanone (Table 6). The percentages of acetaldehyde, 3-methyl butanal, 2,3-butanedione, and 3-hydroxy2-butanone were also positively correlated $(0.39 \leq \mathrm{r} \leq 0.66, \mathrm{p}<$ 0.05 ) with flavor and/or overall acceptance. Our results are consistent with previous studies that reported positive correlations between the 3-methyl butanal contents of loins from AN, HO, and American Wagyu with buttery/beef fat flavor [43]. Both 2-methyl butanal and 3-methyl butanal have been associated with nutty and buttery odors, which positively affect flavor [44]. Other studies have also reported that concentrations of 2,3-butanedione and 3-hydroxy-2-butanone had positive correlations with beef flavor [38,43]. Both 2,3-butanedione and 3-hydroxy-2-butanone are widely used to produce an artificial buttery flavor, and they are also known to impart a buttery flavor to beef [45]. We also found that crude fat and reducing sugar contents as well as the percentages of 3-methyl butanal, 2,3-butanedione, and 3-hydroxy-2-butanone, were highest in KC LT among the three breeds, which may in part contribute to high levels of volatile compounds in $\mathrm{KC}$ beef. This in turn may play a positive role in the superior flavor of KC beef versus the other two breeds for Korean consumers. The impact of 2,3-butanedione and 3-hydroxy-2-butanone on beef flavor in this study may have been minor because these compounds were present in relatively low amounts (less than $1.0 \%$ of all volatile compounds). Further study is warranted to elucidate the role of reducing sugar in the formation of volatile compounds, and their contribution to beef flavor.

In contrast, both crude fat $(-0.71 \leq \mathrm{r} \leq-0.60, \mathrm{p}<0.001)$ and reducing sugar contents $(-0.49 \leq \mathrm{r} \leq-0.39, \mathrm{p}<0.05)$ were negatively correlated with several volatile compounds, including propanal, pentanal, hexanal, heptanal, octanal, and n-pentane (Table 6). None of these volatile compounds showed significant correlations with flavor and overall acceptance, although they were negatively correlated with tenderness and juiciness.

We analyzed the correlation coefficients for FA percentages (in LT fat) with volatile compounds. The percentages of C16:0, C16:1, C18:1n9, and MUFA of LT fat were positively correlated $(0.41 \leq \mathrm{r} \leq 0.78, \mathrm{p}<0.05)$ with acetaldehyde, 2-methyl butanal,

Table 6. Pearson correlation coefficients of chemical composition, physico-chemical parameter, reducing sugar, and sensory traits with volatile compounds of pooled longissimus thoracis from Korean cattle (KC), Holstein (HO), and Angus (AN) steers $(n=36)^{1)}$

\begin{tabular}{|c|c|c|c|c|c|c|c|c|c|c|c|c|c|c|}
\hline Item & Acetaldehyde & Propanal & $\begin{array}{l}\text { 2-Methyl } \\
\text { butanal }\end{array}$ & $\begin{array}{l}\text { 3-Methyl } \\
\text { butanal }\end{array}$ & Pentanal & Hexanal & Heptanal & Octanal & Methanethiol & n-Pentane & 2-Propanone & 2-Butanone & 2,3-Butanedione & $\begin{array}{l}\text { 3-Hydroxy-2- } \\
\text { butanone }\end{array}$ \\
\hline \multicolumn{15}{|l|}{ Chemical composition } \\
\hline Moisture & $-0.73^{* * *}$ & $0.68^{* * *}$ & $-0.68^{* * *}$ & $-0.73^{* * *}$ & $0.72^{* * *}$ & $0.72^{\star * *}$ & $0.66^{* * *}$ & $0.74^{* * *}$ & $-0.38^{*}$ & $0.75^{* * *}$ & $-0.72^{* * *}$ & -0.26 & $-0.69^{* * *}$ & $-0.67^{* * *}$ \\
\hline Crude protein & $-0.50^{* *}$ & $0.39^{*}$ & $-0.35^{*}$ & $-0.43^{* *}$ & $0.42^{*}$ & $0.39^{*}$ & $0.37^{*}$ & $0.40^{*}$ & -0.04 & $0.46^{* *}$ & $-0.44^{* *}$ & 0.08 & $-0.56^{* * *}$ & $-0.59^{* * *}$ \\
\hline Crude fat & $0.70^{* * *}$ & $-0.62^{* * *}$ & $0.65^{* \star *}$ & $0.69^{* * *}$ & $-0.67^{\star \star *}$ & $-0.67^{\star * *}$ & $-0.60^{* * *}$ & $-0.68^{\star * *}$ & $0.35^{*}$ & $-0.71^{* * *}$ & $0.68^{* * *}$ & 0.20 & $0.67^{* * *}$ & $0.63^{* * *}$ \\
\hline \multicolumn{15}{|l|}{ Physico-chemical } \\
\hline \multicolumn{15}{|l|}{ parameters } \\
\hline $\mathrm{pH}$ & $-0.47^{\star *}$ & $0.63^{* * *}$ & $-0.77^{\star * *}$ & $-0.50^{* *}$ & $0.67^{\star \star *}$ & $0.69^{* * *}$ & $0.64^{* \star *}$ & $0.71^{\star * *}$ & $-0.84^{* * *}$ & $0.63^{* * *}$ & $-0.56^{* * *}$ & $-0.69^{* * *}$ & -0.22 & 0.05 \\
\hline Shear force & $-0.43^{* *}$ & $0.52^{* * *}$ & $-0.43^{* *}$ & $-0.60^{* * *}$ & $0.46^{* *}$ & $0.42^{*}$ & $0.47^{* *}$ & $0.49 * *$ & -0.21 & $0.43^{* *}$ & $-0.37^{*}$ & -0.23 & -0.26 & $-0.36^{*}$ \\
\hline Reducing sugar & $0.52^{* *}$ & $-0.40^{*}$ & $0.36^{*}$ & $0.56^{* * *}$ & $-0.44^{* *}$ & $-0.42^{*}$ & $-0.39^{*}$ & $-0.40^{*}$ & -0.01 & $-0.49^{* *}$ & $0.40^{*}$ & -0.04 & $0.39^{*}$ & $0.57^{* * *}$ \\
\hline \multicolumn{15}{|l|}{ Sensory traits } \\
\hline Flavor & $0.40^{*}$ & -0.20 & 0.21 & $0.52^{* * *}$ & -0.23 & -0.26 & -0.17 & -0.27 & -0.12 & -0.29 & 0.28 & -0.07 & $0.54^{* * *}$ & $0.66^{* * *}$ \\
\hline Tenderness & $0.67^{* * *}$ & $-0.61^{* * *}$ & $0.64^{* * *}$ & $0.79^{* * *}$ & $-0.64^{* * *}$ & $-0.67^{* * *}$ & $-0.57^{* * *}$ & $-0.68^{* * *}$ & $0.34^{*}$ & $-0.66^{* * *}$ & $0.64^{* * *}$ & 0.31 & $0.56^{\star * *}$ & $0.58^{* * *}$ \\
\hline Juiciness & $0.58^{* * *}$ & $-0.54^{* * *}$ & $0.55^{* * *}$ & $0.72^{* \star *}$ & $-0.57^{* * *}$ & $-0.60^{* * *}$ & $-0.49^{* *}$ & $-0.57^{\star \star *}$ & 0.28 & $-0.59^{\star \star \star}$ & $0.57^{* * *}$ & 0.29 & $0.62^{* * *}$ & $0.62^{* * *}$ \\
\hline Overall acceptance & $0.39^{*}$ & -0.22 & 0.20 & $0.52^{* * *}$ & -0.25 & -0.28 & -0.19 & -0.28 & -0.13 & -0.31 & 0.31 & -0.03 & $0.52^{\star * *}$ & $0.66^{* * *}$ \\
\hline
\end{tabular}

Correlation coefficient values of several volatile compounds (butanal, butane, carbon disulfide, octane, ethylacetate, benzaldehyde, nonanal, 2-butene, hexane, heptane, 2-heptanone, 2,3-octanedione, dimethyl sulfide, ethanol, isopropyl alcohol, 1-pentanol, 1,3,5-cycloheptatriene) were $r<0.50$ or $p>0.05$, and these data are not shown in this table.

${ }^{*} p<0.05$; ${ }^{* *} p<0.01 ;{ }^{* * *} p<0.001$. 
Table 7. Pearson correlation coefficients between fatty acid composition (\% of fat) and volatile compounds of pooled longissimus thoracis from Korean cattle (KC), Holstein (HO), and Angus (AN) steers $(n=36)^{1)}$

\begin{tabular}{|c|c|c|c|c|c|c|c|c|c|c|c|c|}
\hline Item & Acetaldehyde & Propanal & $\begin{array}{c}\text { 2-Methyl } \\
\text { butanal }\end{array}$ & $\begin{array}{l}\text { 3-Methyl } \\
\text { butanal }\end{array}$ & Pentanal & Hexanal & Methanethiol & Butane & n-Pentane & 2-Propanone & 2,3-Butanedione & $\begin{array}{l}\text { 3-Hydroxy-2- } \\
\text { butanone }\end{array}$ \\
\hline C14:0 & $0.39 *$ & $43^{* *}$ & 0 ** & $0.47^{* *}$ & $46^{* *}$ & $0.47^{* *}$ & $43^{* *}$ & -0.19 & $-0.49^{* *}$ & $46^{* *}$ & 0.21 & 0.15 \\
\hline C16:0 & $0.41^{*}$ & $-0.52^{* * *}$ & $0.59^{* * *}$ & $1 * * *$ & $-0.50^{\text {** }}$ & $-0.50^{* *}$ & $0.43^{* *}$ & -0.17 & $-0.51^{* *}$ & $0.45^{* *}$ & 0.28 & 0.24 \\
\hline C16:1 & $0.58^{* * *}$ & $-0.60 * * *$ & $0.65^{* * *}$ & 0. & $-0.66^{* * *}$ & $-0.66^{* * *}$ & $0.56^{* * *}$ & $-0.35^{\star}$ & $-0.68 * * *$ & $0.65^{* * *}$ & 0.29 & 0.21 \\
\hline C18:0 & $-0.68 * * *$ & $0.69 * * *$ & $-0.74^{* * *}$ & $-0.57^{* * *}$ & $0.74^{* * *}$ & $0.74^{* * *}$ & $-0.60 * * *$ & $0.37^{*}$ & $0.76^{* * *}$ & $-0.71 * * *$ & $-0.52^{* * *}$ & $-0.38^{*}$ \\
\hline C18:1n9 & $0.73^{* * *}$ & $-0.59^{* * *}$ & $0.58^{* * *}$ & $0.42^{* *}$ & $-0.69 * * *$ & $-0.70^{* * *}$ & $0.33^{*}$ & $-0.52^{* * *}$ & $-0.71^{* * *}$ & $0.64^{* * *}$ & $0.61^{* * *}$ & $0.50^{* *}$ \\
\hline C18:2 & $-0.72^{* * *}$ & $0.63^{* * *}$ & $-0.72^{* * *}$ & $-0.68 * * *$ & $0.77^{* * *}$ & $0.79^{* * *}$ & $-0.48^{* *}$ & $0.62^{* * *}$ & $0.83^{* * *}$ & $-0.74^{* * *}$ & $-0.52^{* * *}$ & $-0.43^{* *}$ \\
\hline SFA & $-0.48^{* *}$ & $0.45^{* *}$ & $-0.36^{*}$ & -0.06 & $0.47^{* *}$ & $0.45^{* *}$ & -0.29 & 0.24 & $0.44^{* *}$ & $-0.44^{* *}$ & $-0.42^{*}$ & -0.30 \\
\hline USFA & $0.48^{* *}$ & $-0.44^{* *}$ & $0.36^{*}$ & 0.06 & $-0.46^{* *}$ & $-0.45^{* *}$ & 0.29 & -0.23 & $-0.43^{* *}$ & $0.44^{* *}$ & $0.41^{*}$ & 0.30 \\
\hline MUFA & $0.78^{* * *}$ & $-0.67^{* * *}$ & $0.68^{* * *}$ & $0.47^{* *}$ & $-0.78^{* * *}$ & $-0.78^{* * *}$ & $0.46^{* *}$ & $-0.56^{* * *}$ & $-0.81^{* * *}$ & $0.75^{* * *}$ & $0.61^{* * *}$ & $0.49^{* *}$ \\
\hline PUFA & $-0.73^{* * *}$ & $0.60^{* * *}$ & $-0.70^{* * *}$ & $-0.67^{* * *}$ & $0.75^{* * *}$ & $0.77^{* * *}$ & $-0.43^{* *}$ & $0.63^{* * *}$ & $0.82^{* * *}$ & $-0.72^{* * *}$ & $-0.54^{* * *}$ & $-0.46^{* *}$ \\
\hline
\end{tabular}

SFA, saturated fatty acids; USFA, unsaturated fatty acids; MUFA, monounsaturated fatty acids; PUFA, polyunsaturated fatty acids.

1) Correlation coefficient values of several volatile compounds (butanal, carbon disulfide, octane, ethylacetate, 2-butanone, heptanal, benzaldehyde, octanal, nonanal, 2-butene, hexane, heptane, 2-heptanone, 2,3-octanedione, dimethyl sulfide, ethanol, isopropyl alcohol, 1-pentanol, 1,3,5-cycloheptatriene) were $r<0.50$ or $p>0.05$, and these data are not shown in this table.

${ }^{*} p<0.05 ;{ }^{* *} p<0.01 ;{ }^{* * *} p<0.001$.

3-methyl butanal, and 2-propanone percentages (Table 7). The percentages of C18:1n9 and MUFA of LT fat were also positively correlated $(0.49 \leq \mathrm{r} \leq 0.61, \mathrm{p}<0.01)$ with 2,3-butanedione and 3-hydroxy-2-butanone, which impart a buttery scent to beef. Both C18:1n9, and MUFA are known to be positively associated with beef flavor [32]. Currently, limited information is available on the generation of volatile compounds from specific FAs. In contrast, the C16:0, C16:1, C18:1n9, and MUFA percentages of LT fat were negatively correlated $(-0.81 \leq r \leq-0.50$, $\mathrm{p}<0.01$ ) with several volatile compounds, including propanol, pentanal, hexanal, and n-pentane (Table 7). Pentanal and hexanal can impart pungent, fishy, and grassy odors, which are negatively associated with flavor [46]. Our study showed that these compounds were negatively correlated with tenderness and juiciness, and not correlated with flavor or overall acceptance (Table 6).

The percentages of C18:0, C18:2, and PUFA of LT fat were negatively correlated $(-0.74 \leq \mathrm{r} \leq-0.38, \mathrm{p}<0.05)$ with acetaldehyde, 2-methyl butanal, 3-methyl butanal, 2-propanone, 2,3butanedione, and 3-hydroxy-2-butanone percentages, whereas all of these FAs were positively correlated $(0.60 \leq \mathrm{r} \leq 0.83$, $\mathrm{p}<$ 0.001 ) with propanal, pentanal, hexanal, butane, and n-pentane (Table 7). C18:0 is negatively correlated with beef fat aroma and flavor [8]. Also, PUFAs, including C18:2, are known to be oxidized easily, so they can easily exert a negative effect on beef flavor [47].

Overall, our results indicate that specific FAs can be positively or negatively correlated with volatile compounds. Our data imply that FA composition may in part affect the sensory traits of beef, including flavor, through the generation of volatile compounds.

In our study, both $\mathrm{KC}$ and $\mathrm{HO}$ were raised in Korea with a $\mathrm{KC}$ feed regimen, while $\mathrm{AN}$ were raised in the United States with a typical US cattle feed regimen. These dietary and envi- ronmental differences may affect beef characteristics. Therefore, our study has limitation for interpretation of results.

In conclusion, the fat content, reducing sugar content, and sensory traits of the LT varied among $\mathrm{KC}, \mathrm{HO}$, and $\mathrm{AN}$ steers. The KC LT had the highest fat content and reducing sugar contents, and the best sensory traits (flavor, tenderness, juiciness, and overall acceptance). The fat content and reducing sugar contents were positively correlated with all of the sensory traits, suggesting that these factors may positively affect beef flavor. C16:0, C18:1n9, and MUFA may positively affect sensory traits, whereas C18:2 and PUFA may negatively affect sensory traits. The percentages of different volatile compounds in the LT also varied among the three breeds. The $\mathrm{KC} \mathrm{had}$ the highest percentage of volatile compounds, including acetaldehyde, 3-methyl butanal, and 3-hydroxy-2-butanone, and these compounds were positively correlated with flavor. Our results demonstrated that variations in fat content, reducing sugar content, and FA and volatile compound profiles may contribute to differences in the sensory characteristics of the LT among breeds. The results of this study enhance our understanding of the association of reducing sugar and volatile compound contents with the sensory traits of beef. This information may help in determining beef palatability. This study has limitations of interpretation, considering that beef samples were collected in cattle with different conditions including feeding method, diet type, slaughter weight, and slaughter age and that these factors may affect IMF contents and beef quality and palatability attributes [48].

\section{CONFLICT OF INTEREST}

We certify that there is no conflict of interest with any financial organization regarding the material discussed in the manuscript. 


\section{ACKNOWLEDGMENTS}

This study was supported by the National Research Foundation of Korea (NRF) grant funded by the Korea government (MIST) (2017R1A2B4003207).

\section{REFERENCES}

1. MAFRA. Ministry of Agriculture, Food and Rural Affairs; 2015 [cited 2018 Jan 15]. Available from: http://lib.mafra.go.kr

2. Chung KY, Lee SH, Cho SH, Kwon EG, Lee JH. Current situation and future prospects for beef production in South Korea - A review. Asian-Australas J Anim Sci 2018;31:951-60.

3. KREI. Future agriculture prospect. Naju, South Korea: Korean Rural Economic Institute; 2016.

4. Kim DH, Kim YK, Chung YH, Yoo YM, Park BY. A study on the consumer's attitude to beef: 1 . Consumer's purchasing pattern and preference. J Agric Sci 1993;35:598-601.

5. Kodani Y, Miyakawa T, Komatsu T, Tanokura M. NMR-based metabolomics for simultaneously evaluating multiple determinants of primary beef quality in Japanese Black cattle. Sci Rep 2017;7:1297.

6. Joo ST, Kim GD, Hwang YH, Ryu YC. Control of fresh meat quality through manipulation of muscle fiber characteristics. Meat Sci 2013;95:828-36.

7. Ba HV, Amna T, Hwang IH. Significant influence of particular unsaturated fatty acids and $\mathrm{pH}$ on the volatile compounds in meat-like model systems. Meat Sci 2013;94:480-8.

8. Hwang YH, Joo ST. Fatty acid profiles, meat quality, and sensory palatability of grain-fed and grass-fed beef from Hanwoo, American, and Australian crossbred cattle. Korean J Food Sci Anim Resour 2017;37:153-61.

9. Watkins PJ, Rose G, Warner RD, Dunshea FR, Pethick DW. A comparison of solid-phase microextraction (SPME) with simultaneous distillation-extraction (SDE) for the analysis of volatile compounds in heated beef and sheep fats. Meat Sci 2012;91:99-107.

10. Górska E, Nowicka K, Jaworska D, Przybylski W, Tambor K. Relationship between sensory attributes and volatile compounds of polish dry-cured loin. Asian-Australas J Anim Sci 2017;30: 720-7.

11. Ba HV, Ryu KS, Hwang IH. Flavor characteristics of Hanwoo beef in comparison with other Korean foods. Asian-Australas J Anim Sci 2012;25:435-46.

12. Choi CB, Kwon H, Kim SI, et al. Effects of rice bran, flax seed, and sunflower seed on growth performance, carcass characteristics, fatty acid composition, free amino acid and peptide contents, and sensory evaluations of native Korean cattle (Hanwoo). Asian-Australas J Anim Sci 2016;29:195-203.

13. Neethling J, Hoffman LC, Muller M. Factors influencing the flavor of game meat: a review. Meat Sci 2016;113:139-53.

14. Aliani M, Farmer LJ. Postcolumn derivatization method for determination of reducing and phosphorylated sugars in chicken by high performance liquid chromatography. J Agric Food Chem 2002;50:2760-6.

15. KAPE. Report of Business for Animal Products Grading. Gunpo, Korea: Korea Institute for Animal Products Quality Evaluation; 2013.

16. KAPE. Report of Business for Animal Products Grading. Gunpo, Korea: Korea Institute for Animal Products Quality Evaluation; 2016.

17.AOAC. Official methods of analysis, 15th edn, Association of Official Analytical Chemists, Washington DC, USA: AOAC International; 1996.

18. Piao MY, Jo C, Kim HJ, et al. Comparison of carcass and sensory traits and free amino acid contents among quality grades in loin and rump of Korean cattle steer. Asian-Australas J Anim Sci 2015;28:1629-40.

19. Kim CJ, Lee ES. Effects of quality grade on the chemical, physical and sensory characteristics of Hanwoo (Korean native cattle) beef. Meat Sci 2003;63:397-405.

20. Jayasena DD, Jung S, Kim HJ, et al. Comparison of quality traits of meat from Korean native chickens and broilers used in two different traditional Korean cuisines. Asian-Australas J Anim Sci 2013;26:1038-46.

21. Korean Society of Food Science and Nutrition. Handbook of Experiments in Food Science and Nutrition. Seoul, Korea: Hyoil Publishing Co.; 2000.

22. Piao MY, Yong HI, Lee HJ, et al. Comparison of fatty acid profiles and volatile compounds among quality grades and their association with carcass characteristics in longissimus dorsi and semimembranosus muscles of Korean cattle steer. Livest Sci 2017;198:147-56.

23. Folch J, Lees M, Sloane Stanley GH. A simple method for the isolation and purification of total lipids from animal tissues. J Biol Chem 1957;226:497-509.

24. Cho SH, Seong PN, Kang GH, Park BY, Jung SG. Meat quality and nutritional properties of Hanwoo and imported Australian beef. Korean J Food Sci Anim Resour 2011;31:772-81.

25. Destefanis G, Brugiapaglia A, Barge MT, Dal Molin E. Relationship between beef consumer tenderness perception and WarnerBratzler shear force. Meat Sci 2008;78:153-6.

26. Obuz E, Dikeman ME, Grobbel JP, Stephens JW, Loughin TM. Beef longissimus lumborum, biceps femoris, and deep pectoralis Warner-Bratzler shear force is affected differently by endpoint temperature, cooking method, and USDA quality grade. Meat Sci 2004;68:243-8.

27. Mottram DS, Nobrega ICC. Formation of sulfur aroma compounds in reaction mixtures containing cysteine and three different forms of ribose. J Agric Food Chem 2002;50:4080-6.

28. Ba HV, Hwang I, Jeong D, Touseef A. Principle of meat aroma flavors and future prospect. Latest research into quality control, Dr. Mohammad Saber Fallah Nezhad (Editor); 2012 [cited 2018 Jan 15]. Available from: http://www.intechopen.com/ 
books/latest-research-into-quality-control/principle-of-meataroma-flavors-and-future-prospect.

29. Aliani M, Farmer L. Precursors of chicken flavour II. Identification of key flavour precursors using sensory methods. J Agric Food Chem 2005;53:6455-62.

30. Raes K, Balcaen A, Dirinck P, et al. Meat quality, fatty acid composition and flavor analysis in Belgian retail beef. Meat Sci 2003;65:1237-46.

31. Jeong D, Oh MR, Seong PN, et al. Comparison of meat quality traits, free amino acid and fatty acid on longissimus lumborum muscles from Hanwoo, Holstein and Angus steers, fattened in Korea. Korean J Food Sci An 2012;32:591-7.

32. Anderson DA, Kisellan JA, Watt BK. Comprehensive evaluation of fatty acid in beefs. J Am Diet Assoc 1975;67:35-41.

33. Huang TC, Ho CT. Flavors and flavor generation of meat products. In: Hui YH, editor. Handbook of meat and meat processing. Boca Raton, FL, USA: CRC Press; 2012. p. 109-16.

34. Fujimaki M, Kato S, Kurata T. Pyrolysis of sulfur-containing amino acids. Agric Biol Chem 1969;33:1144-51.

35. Mottram. Flavour formation in meat and meat products: a review. Food Chem 1998;62:415-24.

36. Shahidi F, Rubin LJ, Souza LA. Meat flavor volatiles: a review of the composition, techniques of analysis, and sensory evaluation. Crit Rev Food Sci Nutr 1986;24:141-243.

37. Min DB, Ina K, Peterson RJ, Chang SS. Preliminary identification of volatile flavor compounds in the neutral fraction of roast beef. J Food Sci 1979;44:639-42.

38. Legako JF, Dinh TTN, Miller MF, Adhikari K, Brooks JC. Consumer palatability scores, sensory descriptive attributes, and volatile compounds of grilled beef steaks from three USDA quality grades. Meat Sci 2015;112:77-85.

39. El-Magoli SB, Laroia S, Hansen PMT. Flavor and texture characteristics of low fat ground beef patties formulated with whey protein concentrate. Meat Sci 1996;42:179-93.

40. Mandell IB, Buchanan-Smith JG, Campbell CP. Effects of forage vs grain feeding on carcass characteristics, fatty acid composition, and beef quality in Limousin-Cross steers when time on feed is controlled. J Anim Sci 1998;76:2619-30.

41. Garmyn AJ, Hilton GG, Mateescu RG, et al. Estimation of relationships between mineral concentration and fatty acid composition of longissimus muscle and beef palatability traits. J Anim Sci 2011;89:2849-58.

42. O'Quinn TG. Identifying consumer preferences for specific beef flavor characteristics [dissertation]. Fort Collins, CO, USA: Colorado State University; 2012.

43. O'Quinn TG, Woerner DR, Engle TE, et al. Identifying consumer preferences for specific beef flavor characteristics in relation to cattle production and postmortem processing parameters. Meat Sci 2016;112:90-102.

44. Giri A, Osaka K, Ohshima T. Identification and characterization of headspace volatiles of fish miso, a Japanese fish meat based fermented paste, with special emphasis on effect of fish species and meat washing. Food Chem 2010;120:621-31.

45. Machiels D, Istasse L, van Ruth SM. Gas chromatography olfactometry analysis of beef meat originating from differently fed Belgian Blue, Limousin and Aberdeen Angus bulls. Food Chem 2004;86:377-83.

46. Kaseleht K, Leitner E, Paalme T. Determining aroma-active compounds in Kama flour using SPME-GC/MS and GColfactometry. Flavour Fragr J 2011;26:122-8.

47. Wood JD, Richardson RI, Nute GR, et al. Effects of fatty acids on meat quality: a review. Meat Sci 2003;66:21-32.

48. Park SJ, Beak SH, Jung DJS, et al. Genetic, management, and nutritional factors affecting intramuscular fat deposition in beef cattle. Asian-Australas J Anim Sci 2018;31:1043-61. 